\title{
12/12 HLA Match
}

National Cancer Institute

\section{Source}

National Cancer Institute. 12/12 HLA Match. NCI Thesaurus. Code C158472.

Complete HLA matching for HLA-A,-B,-C,-DRB1,-DQB1, and -DP loci. 